Canadian

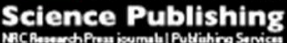

Biochemistry and Cell Biology

Biochimie et biologie cellulaire

\title{
Molecular dynamics of FMRP and other RNA-binding proteins in MEG-01 differentiation: the role of $\mathrm{mRNP}$ complexes in non-neuronal development
}

\begin{tabular}{|r|l|}
\hline Journal: & Biochemistry and Cell Biology \\
\hline Manuscript ID & bcb-2015-0131.R1 \\
\hline Manuscript Type: & Article \\
\hline Date Submitted by the Author: & O4-Feb-2016 \\
\hline Complete List of Authors: & $\begin{array}{l}\text { McCoy, Marie; Université de Sherbrooke, Biochemistry department } \\
\text { Duchesneau-Poliquin, David; Université de Sherbrooke, Biochemistry } \\
\text { Department } \\
\text { Corbin, Francois; Université de Sherbrooke, Biochemistry Department }\end{array}$ \\
\hline Keyword: & FMRP, Cellular differentiation, Cytoskeleton, MEG-01, RNA-binding protein \\
\hline
\end{tabular}

\section{SCHOLARONE}

Manuscripts 
Molecular dynamics of FMRP and other RNA-binding proteins in MEG-01 differentiation: The role of $\mathrm{mRNP}$ complexes in non-neuronal development

\author{
McCoy M, Poliquin-Duchesneau D, Corbin, F
}

Department of Biochemistry, Université de Sherbrooke, Sherbrooke, QC, Canada 


\begin{abstract}
Asymmetrically differentiating cells are formed with the aid of RNA-binding proteins (RBPs), which can bind, stabilize, regulate and transport target mRNAs. The loss of RBPs in neurons may lead to severe neurodevelopmental diseases such as the Fragile X Syndrome with the absence of the Fragile X Mental Retardation Protein (FMRP). Since the latter is ubiquitous and shares many similarities with other RBPs involved in the development of peripheral cells, we suggest that FMRP would have a role in the differentiation of all tissues where it is expressed. A MEG-01 differentiation model was therefore established to study the global developmental functions of FMRP. PMA induction of MEG-01 cells causes important morphological changes driven by cytoskeletal dynamics. Cytoskeleton change and colocalization analyses were performed by confocal microscopy and sucrose gradient fractionation. Total cellular protein content and de-novo synthesis were also analyzed. Microtubular transport mediates the displacement of FMRP and other RBP-containing mRNP complexes towards regions of the cell in development. De-novo protein synthesis decreases significantly upon differentiation and total protein content composition is altered. Since those results are comparable to those obtained in neurons, the absence of FMRP would have significant consequences in cells everywhere in the body. The latter should be further investigated in order to give a better understanding of the systemic implications of imbalances of FMRP and other functionally similar RBPs.
\end{abstract}

Keywords: FMRP, cellular differentiation, RNA-binding protein, cytoskeleton, MEG-01

\title{
Résumé
}

La formation de cellules différenciées est facilitée par l'intervention des protéines liant l'ARN qui lient, stabilisent, régulent et transportent des ARNms ciblés. L’absence de ces protéines au 
niveau des neurones peut conduire à des maladies neurodéveloppementales sévères telles que le syndrome du X fragile qui résulte de l'absence de FMRP (Fragile X Mental Retardation Protein). Puisque cette dernière est ubiquitaire et partage plusieurs similarités avec d'autres protéines liant l'ARN, qui sont impliquées dans le développement de cellules périphériques, nous suggérons que FMRP aurait un rôle dans la différenciation de tous les tissus où il est exprimé. Un modèle de différentiation avec les MEG-01 a donc été développé afin d'étudier les fonctions globales de FMRP dans le développement. Les MEG-01, sous l'action du PMA, subissent des changements morphologiques importants guidés par la réorganisation du cytosquelette. Des approches par microscopie confocale et par sédimentation sur gradient de sucrose ont été utilisées afin de mieux caractériser ces changements et de vérifier s'il y a colocalisation de protéines-clés. Le contenu cellulaire complet en protéine ainsi que la synthèse protéique de novo ont également été mesurés. Le microtuble jouerait un rôle important dans le déplacement de FMRP et des autres protéines liant l'ARN vers les régions de la cellule en développement. Durant cette différentiation, la synthèse protéique de novo diminue significativement et la composition protéique est modifiée. Puisque ces résultats sont comparables à ceux observés au niveau des neurones, l'absence de FMRP aurait donc des conséquences significatives dans toutes les cellules de l'organisme. Des travaux additionnels sont nécessaires afin de mieux comprendre les impacts systémiques d'un dérèglement des niveaux de FMRP ou d'autres protéines similaires impliquées dans le métabolisme de l'ARN.

Mots-clés : : FMRP, Différenciation cellulaire, Protéine de liaison à l'ARN, cytosquelette, MEG01 


\section{$\underline{\text { Introduction }}$}

Cellular differentiation is a process by which a simple progenitor cell may specialize and acquire a mature, functional and complex form, thereby permitting the zygote to develop or for tissues to regenerate and to elaborate their architecture. Cell polarity and orientation in relation to the environment is established by asymmetric distribution of cellular proteins (Bassell et al. 1999; Xing and Bassell 2013). This important phenomenon is commonly driven by the localization of mRNAs (Pratt and Mowry 2013; Xing and Bassell 2013). During this mRNA transport, RNAbinding proteins (RBPs) exert tight regulation of protein translation to permit the translation of mRNAs only once they have reached the subcellular region requiring their expression (Bassell et al. 1999; Huang and Richter 2004; Xing and Bassell 2013) for the acquisition of new cellular functions (Muller et al. 2007). Many RBPs have been shown to play a role in the binding, stabilization, transport and regulation of their mRNA targets, especially during cellular differentiation. Should one of these key RBPs be missing, a developmental anomaly may well arise, as is the case with the Fragile X Syndrome (FXS).

FXS is the most common form of inherited intellectual disability. It is a spectrum disorder also characterized by macroorchidism, flat feet, craniofacial anomalies and hyperflexible joints (Saldarriaga et al. 2014). The syndrome results from a CGG repeats expansion at the 5' UTR of the FMR1 gene associated with methylation of a CpG island methylation upstream of the FMR1 gene which leads to an absence of expression of Fragile X Mental Retardation Protein (FMRP) (Xu et al. 2013). FMRP is a highly conserved RBP having well know RNA-binding motifs; one RGG-box at its C-terminal and two centrally-located KH domains (Ashley et al. 1993). The RGG-box has a B-turn motif having a great affinity for G-quadruplex RNA as recently 
confirmed and detailed using crystal structure (Vasilyev et al. 2015). KH domains also seem to play a major role in RNA binding. For instance, FMRP has several isoforms and the binding capacity of the KH2 for mRNA can be altered if splice variants lengthen or shorten the KH2 binding domain, or in presence of the well-known I304N mutation (Ascano et al. 2012; De Boulle et al. 1993). Though the recognition domains are known, no specific and precise targets have been identified suggesting that FMRP affects a wide subset of mRNA targets. Darnell et al. have shown, using CLIP protocols, that FMRP interacts with 842 target mRNAs, 28 of which are related to autism spectrum disorders such as neuroligin 3, neurexin 1, shank3, PTEN, TSC2, neurofibromatosis 1, suggesting an alteration in the functional levels of the corresponding proteins (Darnell et al. 2011). Additionally, one third of FMRP CLIP targets encode presynaptic proteins. Other FMRP mRNA targets are also involved in ERK and mTOR pathways, NMDA receptors, small GTPase receptors, adhesion molecules between two cells (Hoeffer and Klann 2010; Kelleher and Bear 2008).

Still, the affinity between FMRP and its mRNA targets leads to the formation of messenger ribonucleoproteins (mRNPs) within polyribosomes (Corbin et al. 1997; Qurashi et al. 2012). FMRP is most likely a translational repressor and its absence results in structural anomalies where dendritic spines appear abundant, long, thin and immature (Darnell and Richter 2012). These anomalies explain the loss of synaptic plasticity which leads to neurodevelopmental and cognitive problems (Antar and Bassell 2003; Bagni and Greenough 2005; O'Donnell and Warren 2002). 
Although FMRP is highly expressed in neurons, it is a ubiquitous protein (Khandjian et al. 2004) that would play a role in other tissues (Oostra and Nelson, 2006). FMRP shares common functions with other RBPs involved in cellular differentiation: it stabilizes mRNAs, regulates their translation (Gatto and Broadie 2010), and it also aids in mRNA transport and local synthesis (Bardoni et al. 2006; Callan et al. 2012; Davidovic et al. 2005). FMRP was shown to be expressed in early stages of development in mouse model (Khandjian et al. 1995) and even during oocytes maturation (Takahashi et al. 2015) are factors which suggest specific protein functions which would be of particular importance throughout the cell development. These considerations only support the concept that FMRP may play a more generalized role during development and cell differentiation.

Our objective is therefore to determine functions of FMRP during cellular differentiation outside the neural system. For the purpose of enlarging the perspective on FMRP's influence in development, the immortalized cell line MEG-01 was used as an inducible model of cellular differentiation. MEG-01 is commonly used to study mechanisms of megakaryocytic maturation and platelet formation. It is a well characterized model which is simple to induce into differentiation, and the different morphological aspects of the steps involved in cell maturation are recognizable (Hansen et al. 2013). As is the case in neurons, an important reorganization of the cytoskeleton is required for the formation of cytoplasmic extensions, which eventually become proplatelets. Proplatelets then mature to form preplatelets and release platelet-like particles (PLPs), which highly resemble natural platelets in composition, morphology, as well as in function (Battinelli et al. 2001). 
In the current study, using several approaches, we show that MEG-01 cell differentiation triggers the displacement of polyribosomes-bound FMRP towards regions of the cell in development. The microtubular network plays a major role in this reorganization. These important observations parallel what was previously observed in neurons and suggest that the absence of FMRP could be of greater consequence than previously anticipated and should therefore be further investigated.

\section{$\underline{\text { Methods }}$}

For diagram of experimental design, refer to Supplementary Figure S4.

\section{MEG-01 culture and differentiation}

MEG-01 (cat. CRL-2021, ATCC) were maintained in culture in RPMI medium completed with 10\% FBS, 1\% L-glutamine and 1\% penicillin/streptomycin (Wisent) in T75 flasks for no more than 25 passages. Cells were activated by addition of $10 \mathrm{nM}$ phorbol-12-myristate-13-acetate (PMA) (cat. 524400, Calbiochem) to cells, passed the day prior to activation, and left to differentiate for one week, replacing the medium and PMA twice every week. When applicable, the following cytoskeleton-modulating agents were added simultaneously to PMA induction of MEG-01 cells: $10 \mu \mathrm{M}$ taxol (paclitaxel, cat. 580555, Calbiochem), $10 \mu \mathrm{g} / \mathrm{ml}$ colchicine (cat. C9754, Sigma), $1 \mu \mathrm{M}$ jasplakinolid (cat. J7473, InVitrogen), or $10 \mu \mathrm{M}$ cytochalasin D (cat. 250255, Calbiochem).

\section{Immunofluorescence}

MEG-01 cells were PMA-activated in six well plates containing autoclaved microscope coverslips at the bottom of each well. Differentiating cells adhered to coverslips, while 
proliferating cells needed to be quickspun, resuspended in a minimal volume of $2 \%$ PFA in PBS pH 7.4 and spread evenly on the coverslip at high concentrations so as to maximize adhesion to the surface. $2 \%$ PFA/PBS pH 7.4 was also added to adhesive, activated cells directly on the coverslips. The fixation solution was left for 30 minutes at room temperature, then washed twice with cold PBS pH 7.4. When applicable, $5 \mu \mathrm{g} / \mathrm{ml}$ of WGA was added to label membranes for 10 minutes in the dark before fixation and washed twice. Cells were permeabilized in cold $0.05 \%$ Tween-20 in PBS for 5 minutes, followed by $0.2 \%$ Triton X-100 in PBS pH 7.4 for 10 minutes at $4^{\circ} \mathrm{C}$. Coverslips were blocked for 1 hour at room temperature or overnight at $4{ }^{\circ} \mathrm{C}$ in $5 \% \mathrm{milk} / 2 \%$ BSA/PBS pH 7.4. They were then washed twice in cold $0.05 \%$ Tween-20/PBS pH 7.4 and exposed to 15U/ml of Alexa 488-conjugated Phalloidin (Phallotoxin) (cat. A12379, InVitrogen) to label F-actin for a period of 20 minutes in the dark. Coverslips were washed and incubated for 1 hour at room temperature or overnight at $4^{\circ} \mathrm{C}$ in the presence of primary antibodies diluted in $2 \% \mathrm{BSA} / \mathrm{PBS} \mathrm{pH} 7.4$, washed twice in wells and incubated for 1 hour in the dark at room temperature, in diluted Alexa-conjugated secondary antibodies, combined with $100 \mathrm{ng} / \mathrm{ml} \mathrm{DAPI}$. Coverslips were washed twice in $0.05 \%$ Tween-20/PBS, once in PBS, mounted with Vectashield (cat.H-1000, Vector) onto prewashed microscope slides and sealed with nail polish (Revlon, Top Speed). Slides were kept in the dark at $4^{\circ} \mathrm{C}$ until image acquisition.

Confocal microscopy was performed using an Olympus FV1000 confocal microscope, equipped with 4 lasers $(405,453,515$ and $633 \mathrm{~nm})$ with $40 \mathrm{X}$ and $60 \mathrm{X}$ oil submersion objectives. Lasers at 405nm (DAPI), 453 (Phalloidin, WGA and Alexa Fluor 488) and 633 (Alexa Fluor 647) were used for excitation of slide samples. Images for 3-5 different layers of each cell (3-6 cells per 
slide) were acquired and images were prepared and analyzed using Fluo View software. Colocalization analysis was performed for overlapping 433 and $647 \mathrm{~nm}$ fluorescence emissions.

Primary antibodies used were: B-tubulin (cat. ab15568, Abcam), EIF4E (cat. 610270, BD Biosciences), a-actinin (cat. MAB1682, Chemicon), FMRP 1C3 clone (cat. MAB2160, Millipore), RPL26 (cat. ab59567, Abcam), PABP1 (cat. P6246, Sigma), P-selectin (cat. 3633R100, BioVision), RPL7a (cat. NB 100-2277, Novus Biologicals), Calnexin (cat. sc-6465-R, Santa Cruz), GPIIb/IIIa (cat. sc-53358, Santa Cruz), CD42b (cat. sc-271171, Santa Cruz). Secondary antibodies were: Goat anti-mouse Alexa Fluor 647 (cat. A21236, InVitrogen), Goat anti-rabbit Alexa Fluor 488 (cat. A11070, InVitrogen), and Goat anti-rabbit Alexa Fluor 647 (cat. A21245, InVitrogen).

\section{Differential centrifugation}

Cells were cultivated as described and activated for one week with PMA. Upon acquisition of mature morphology, with long and elaborate filopods as well as the appearance of platelet-like particles in the medium, cells were considered fully differentiated and were finally lyzed for differential centrifugation. MEG-01 cells were scraped, harvested and centrifuged for 3 minutes at $300 \mathrm{G}, 4^{\circ} \mathrm{C}$. They were then washed twice in cold PBS pH 7.4 and resuspended in lysis buffer composed of: $25 \mathrm{mM}$ Tris- $\mathrm{HCl} \mathrm{pH} 7.4,5 \mathrm{mM} \mathrm{MgCl}_{2}, 100 \mathrm{mM} \mathrm{KCl}, 100 \mathrm{mM} \mathrm{NaF}, 10 \mu \mathrm{g} / \mathrm{ml}$ Aprotinin (cat. A1153, Sigma-Aldrich), 1mM PMSF (cat. 78830, Fluka), 1\% NP-40, 25 U/ml RNAsin (cat. N2111, Promega), 1mM DTT (cat. D0632, Sigma-Aldrich). For lysis buffer assays, the following components were added to the standard lysis buffer: DOC $0.5 \%$ (cat. D6750, Sigma-Aldrich), EDTA 50mM (cat. S311-500, Fisher), or RNAse 25 U/ml (cat. 78020Y, USB). 
MEG-01 cells were lyzed for 20 minutes on ice, homogenized with a $1 \mathrm{ml}$ syringe equipped with a $27 \mathrm{G}$ needle (1cc, Terumo), and centrifuged for 5 minutes at $2380 \mathrm{G}, 4^{0} \mathrm{C}$ to obtain a P2pellet. The S2supernatant was centrifuged again for 15 minutes at $16000 \mathrm{G}, 4^{0} \mathrm{C}$ to obtain the P16pellet.The S16supernatant was centrifuged for 1:30 hours at $100000 \mathrm{G}, 4^{0} \mathrm{C}$ to obtain final P100pellet and S100 supernatant.

Samples were resuspended in PBS, homogenized with 27G needled syringes, mixed with sample buffer, boiled for 5 minutes at $98^{\circ} \mathrm{C}$, and homogenized once more before storage at $-20^{\circ} \mathrm{C}$. The protein content of each cellular fraction collected was determined by SDS-PAGE $(7.5 \%$ and $10 \%$ polyacrylamide, $1.5 \mathrm{~mm}$ ), followed by Western Blotting. Primary antibodies used in this assay were the same as the aforementioned used in immunofluorescence, and secondary isotypetargeted and fluorophore-conjugated antibodies included: Alexa Fluor 680 and Alexa Fluor 800 (InVitrogen). Protein ladder from LiCOR was used to determine the molecular weight of each corresponding band detected. The labelled nitrocellulose membranes were then analyzed using a LiCOR scanner which detects fluorescent emission at 700 and 800nm.

\section{Sucrose gradient}

Similarly to differential centrifugations, cells were differentiated in culture and lyzed. The cell lysate was then centrifuged in a microcentrifuge for 10 minutes at $10000 \mathrm{G}, 4^{0} \mathrm{C}$ to obtain the P10 pellet, and the S10 supernatant. The P10 fraction was resuspended in PBS and denatured in sample buffer as described above. TheS10 supernatant was placed atop of a sucrose gradient composed of $15,23,31,38$ and $45 \%(\mathrm{w} / \mathrm{w})$ sucrose in a $0.1 \%$ DEPC-treated solution of $25 \mathrm{mM}$ Tris-Base $\mathrm{pH} 7.4,100 \mathrm{mM} \mathrm{KCl}$ and $5 \mathrm{mM} \mathrm{MgCl}_{2}$ in $11 \mathrm{ml}$ SETON tubes. Gradients were 
centrifuged in a Beckman centrifuge with an MSL-50 rotor for 2 hours at $300000 \mathrm{G}, 4^{0} \mathrm{C}$ to separate molecular components of the sample to corresponding densities across the gradient. Following centrifugation, gradients were fractionated using a tube piercer, a Tris pump and a UA-6 absorbance detector (Teledyne ISCO). Fractions of an equal volume were collected and changes in absorbance at $254 \mathrm{~nm}$ were traced during fractionation of the gradient, starting from the top of the gradient and ending with the bottom and denser fractions of the gradient. Sample buffer was added to the fractions and samples were boiled before being stored at $-20^{\circ} \mathrm{C}$ until SDS-PAGE and Western Blot analyses were performed for each fraction recovered.

\section{Fluorescence Assisted Cell Sorting (FACS)}

MEG-01 cells were differentiated in culture for 1 week, pelletted and washed twice in PBS pH 7.4 as described earlier. Cells were resuspended in PBS pH 7.4 at $2.5 \times 10^{5}$ cells $/ \mathrm{ml}$, using $1 \mathrm{ml}$ of cells per sample. A quickspin was performed, and cells were resuspended in 1\% PFA for a 30minute fixation. Cells were washed in $0.1 \%$ BSA/PBS pH 7.4 and permeated using standard solution $\left(0.025 \%\right.$ Tween-20 in $0.1 \%$ BSA/PBS pH 7.4) for 20 minutes at $4{ }^{\circ} \mathrm{C}$. Then, cells were incubated in the presence of primary antibodies diluted in standard solution overnight at $4^{0} \mathrm{C}$. The same primary antibodies were used as in immunofluorescence and Western Blotting assays. Washing of labelled samples was performed in standard solution, followed by an incubation of 1 hour in the dark, with fluorophore-conjugated secondary antibodies Alexa Fluor 488 (anti-rabbit) and Alexa Fluor 647 (anti-mouse) (InVitrogen), diluted in standard solution. MEG-01 cells were washed and resuspended in a small volume of standard solution containing $5 \mu \mathrm{g}$ of propidium iodide (P4170, Sigma-Aldrich) for nucleic acid labelling at room temperature, 30 minutes prior to FACS reading. Channels were set for the detection of Alexa Fluor 488 (FL-1), Alexa Fluor 
647 (FL-3), propidium iodide (FL-2), and for each sample, forward scatter as well as side scatter was measured as well. 10000 events per sample were accumulated, excluding noise signals. Gating was adjusted to include in the count only those cells having correctly permeabilized to incorporate propidium iodide, as well as cells whose size corresponds to the healthy, living population according to forward scatter and sides scatter plots.

\section{(35)S methionine/cysteine incorporation assay}

De-novo protein synthesis was studied using the EasyTag EXPRE (35)S (35)S protein labelling kit (NEG772002MC, PerkinElmer). MEG-01 cells were differentiated in culture for 1 week as described and medium was replaced one day prior to the experiment. The following day, these cells were washed once in completed RPMI medium lacking methionine and cysteine (Wisent, $350-050-E L)$, and incubated for 15 minutes in a flask at $37^{\circ} \mathrm{C}$ with this same medium to deplete cellular methionine/cysteine. Radio-labelled amino acids were then added to a final concentration of $100 \mu \mathrm{Ci} / \mathrm{ml}$ in a total volume of $5 \mathrm{ml}$, then were incubated at $37^{\circ} \mathrm{C}$ for 1 hour to permit protein synthesis and incorporation of (35)S radioactivity to occur. Total extracts were prepared, or alternatively, lysis was performed on radio-labelled cells for differential centrifugations. Samples were prepared as described for differential centrifugations and separated by SDS-PAGE on NUPAGE 4-12\% gradient gels (InVitrogen) using MOPS buffer. Gels were fixed in a 10\% acetic acid/1\% glycerol solution for 30 minutes, dried and exposed for 1 hour to a phosphor screen at room temperature, followed by detection and analysis of bands using a Typhoon PhosphorImager (Molecular Dynamics).

\section{$\underline{\text { Results }}$}

\section{Establishment and characterization of the MEG-01 differentiation model}


PMA induction of the cells triggered individual growth, adherence to culture flask surfaces, and formation of filopodal extensions which became more elaborate with time, as observed by light phase microscopy during differentiation. Full MEG-01 maturation is usually reached within one week of differentiation in culture, with the appearance of small PLPs in suspension in the culture medium. The activated population obtained was mostly heterogeneous, with a fraction of cells adhering, with or without filopods, and another fraction in suspension, actively differentiating, or in the process of apoptosis as observed by Trypan blue coloring of cells (data not shown). Thus, all stages of differentiation can be observed simultaneously in one single flask of activated MEG-01 cells.

Immunofluorescent labelling of the cytoskeleton and FMRP content revealed their subcellular distribution in proliferating and differentiating MEG-01 cells. Thus highlighting the changes in morphology and FMRP localization, it was possible to more thoroughly characterize the different stages of MEG-01 differentiation. Non-activated cells are shown by immunofluorescence, with a small diameter of approximately $10 \mu \mathrm{m}$, replicating in suspension with one relatively prominent nucleus (Figure 1). Upon addition of PMA, cells rapidly become larger with expansion of the nucleus as they undergo the well-known stage of endomitosis, where no more cell division takes place, though DNA is replicated (Baatout et al. 1999). Differentiating MEG-01 cells undergo significant cytoskeletal reorganization, and changes in morphology are evident as the cytoplasm expands and reaches out to form filopod-like structures which then elongate away from the nucleus. These structures are the proplatelets, very active regions of the cell where platelet-like shapes called preplatelets accumulate at the extremities of 
these cytoplasmic extensions throughout the final stages of MEG-01 maturation. Proplatelets are gradually fragmented, released from the cell body to produce individual PLP (Figure 1).

Morphological changes triggered the displacement of FMRP throughout cell differentiation. When cells are in proliferation, as well as during the early stages of differentiation, FMRP is mainly cytoplasmic and perinuclear in distribution as classically reported in most cultured cells (Khandjian et al. 1996). Some FMRP signals can also be detected in the nucleus. As soon as points of cytoplasmic protrusion are established, FMRP seems to be gathered in those peripheral regions. It gradually localizes itself further away from the nucleus, as proplatelets are elongated to distances of up to $100 \mu \mathrm{m}$ typically.

\section{Subcellular distribution of FMRP and polyribosomes during differentiation}

In order to confirm our immunofluorescence data, we investigated whether FMRP's distribution within the cell changed during the processes of cell maturation using cell fractionation studies. Referring back to figure $1 \mathrm{~b}$, where every step of MEG-01 differentiation is visually depicted by immunofluorescence, the distribution of FMRP can be followed. As filopods are formed, highlighted by a green F-actin label, the distribution of FMRP goes from being mostly perinuclear to being more peripherally-oriented, extending out into elongating cytoplasmic extensions. This suggests that some form of transport mechanism should become involved with FMRP following MEG-01 induction.

In order to further characterize the subcellular distribution of FMRP throughout the process of MEG-01 differentiation, cell fractionation was performed by two complementary methods. First, 
to get a general idea of FMRP distribution throughout different cellular compartments, differential centrifugations of MEG-01 lysates were carried out and four different fractions were obtained. Classical pellets P2 (cytoskeleton, nucleus and membrane fragments), P16 (mitochondria), P100 (polyribosomes, lysosomes and peroxysomes), as well as supernatant S100 (ions and other soluble biomolecules) were obtained and Western Blot analysis was performed on each fraction. As shown in Figure 2a, FMRP in proliferating cells is mainly detected in the P100 and P2 fractions, whereas upon differentiation, FMRP is displaced almost entirely towards the P2 fraction (Figure 2a). The large subunit ribosomal protein, RPL7a, also appears to be displaced similarly to FMRP.

This interesting distributional shift was additionally confirmed by sucrose gradient fractionation of the polyribosomal fraction of MEG-01 lysates (Figure 2b), where FMRP's and RPL7's distribution was determined again by Western Blot analysis. Ribosomal RNA throughout the gradient was also monitored by $254 \mathrm{~nm}$ absorbance readings, from which curves were automatically traced by the apparatus. In proliferating MEG-01 cells, FMRP is retrieved in the denser polyribosomal fractions, as shown by both the absorbance tracings and Western Blot analyses. When MEG-01 cells differentiate, their polyribosomal fraction becomes undetected, as both rRNA absorbance readings and Western Blot bands for FMRP and RPL7 are absent within typically corresponding polyribosomal fractions, confirming the displacement of FMRP and polyribosomes which was previously observed in $\mathrm{P} 2$.

\section{Establishment of potential interactions between FMRP and structural constituents of the cell involved in FMRP transport}


By immunofluorescence and confocal microscopy, colocalization assays were performed to determine potential structures which may be involved in FMRP transport across the cell. First, the cytoskeleton, which commonly mediates the transport of organelles as well as various RBPs, was investigated. Microtubules, here identified using B-tubulin targeting primary antibodies secondarily labelled with a $488 \mathrm{~nm}$ fluorophore, revealed a high degree of colocalization with FMRP, which was simultaneously labelled using a $647 \mathrm{~nm}$ fluorophore (Figure 3a). This colocalization can be observed at all stages of differentiation. In contrast, colocalization between FMRP and actin filaments as determined by using Alexa Fluor-conjugated Phalloidin, which binds F-actin strongly and specifically, proves to remain minimal, limited to the center of the nucleus as well as to the cellular periphery (Figure $3 b$ ). Thus, it can be hypothesized that the microtubules, rather than the actin filaments, are the cytoskeletal constituents responsible for mediating mRNP transport, displacing FMRP throughout the cell during differentiation as occurs in neurons with RNA granules.

FMRP is known to form mRNP complexes with polyribosomes in translation (Corbin et al., 1997). Since the rough endoplasmic reticulum (RER) is well known for its numerous and surrounding polyribosomes actively synthesizing proteins, the colocalization between FMRP and the RER was evaluated using the Calnexin protein as a marker. The two proteins do colocalize to some extent, particularly in perinuclear regions, as well as at bases and openings of filopodal extensions (Figure 3c). However, colocalization does not reach the absolute extremities of cytoplasmic extensions as far out as that of the cytoskeleton with FMRP. Therefore, if the RER is involved in the partial displacement of FMRP in MEG-01 cells, it cannot be the sole major 
player in mRNP transport as could be the microtubular system or another far-reaching component of the cytoskeleton.

Since the cytoskeleton is typically involved in morphological changes during differentiation, as well as in the transport of mRNPs throughout the cell; and since FMRP colocalizes best with the microtubules, the cytoskeletal dynamics became a new branch of interest. In order to ascertain the importance of full dynamic freedom of both actin filaments and microtubules in MEG-01 maturation, differentiation was triggered in the presence of cytoskeleton-modulating drugs. The following drugs were used in these assays: cytochalasin D (actin filament destabilizer), jasplakinolid (actin filament stabilizer), colchicine (microtubule destabilizer), and taxol (microtubule stabilizer). Though the mechanisms involved in morphological anomalies are different under the influence of the modulators when compared to pathological developmental issues such as those of the FXS, similar results were obtained by interfering with any one of the cytoskeletal dynamics targeted; cellular maturation becomes atypical. These treatments, modulating MEG-01 cells results in an absence of mature proplatelets (Supplementary Figure S1a), similar to the immature dendrites of FXS neurons. Nonetheless, in presence of stabilizing agents, some rather dense filopods can be formed, though they remain short and abnormally curved. Conversely, destabilizing agents seem to weaken the forming structures. In all cases, any unbalancing of cytoskeletal dynamics seems prevent the proper morphological progress of MEG01 cells in differentiation.

The distribution of FMRP and ribosomes following differentiation in presence of cytoskeletonmodulating agents was also investigated by extracting cells and performing differential 
centrifugations, followed by SDS-PAGE and Western Blot analysis (Supplementary Figure S1b). Typical distribution of FMRP was obtained in non-treated differentiated MEG-01 cells, though FMRP's subcellular localization was altered in presence of any one of the cytoskeleton modulators which had an impact on final MEG-01 morphology. However, the most drastic of all influences exerted on the cells in differentiation is that of the colchicine, inhibitor of microtubule polymerization, which appears to trap all of FMRP in the P2 fraction - that of the cytoskeleton. This suggests that microtubules could be of particular importance in the differentiation of MEG01 cells, both at the level of FMRP displacement, as well as in the acquisition of mature cellular morphology.

\section{Colocalization assays of FMRP with other potentially co-transported RBPs}

To determine whether other RBPs are redistributed similarly to FMRP across the cell during differentiation, colocalization by immunofluorescent labelling of these proteins followed by confocal microscopy was performed. We showed that ribosomal proteins RPL7a (Figure 4a), as well as L26 (data not shown), colocalize perfectly with cytoplasmic FMRP. Additionally, ribosomal proteins are found in the nucleus at relatively high levels, which seem to surpass those of nuclear FMRP. Colocalization of FMRP with ribosomes indicates the presence of mRNP complexes, which have also been identified in strong numbers within neurons.

EIF4E is a translation factor which binds mRNAs to be translated. For questions of antibody's isotype compatibility, colocalization assays were performed for EIF4E and RPL7a, which were shown to colocalize perfectly with cytoplasmic FMRP. Immunofluorescent labelling indicates an EIF4E signal that is very intense in the nucleus, although FMRP is typically less prominent in 
this region of the cell (Figure 4b). EIF4E and RPL7a colocalize to a very high degree throughout the cytoplasm (as does FMRP), and also to some extent within the nucleus. Initially, EIF4E is less cytoplasmically oriented than FMRP in non-differentiating cells. However, the induction of MEG-01 differentiation appears to trigger a clear displacement of EIF4E from the nucleus to the cytoplasm, similar to the FMRP shift observed in differential centrifugation assays and therefore suggesting a common behaviour which is perhaps made more obvious with EIF4E labelling. The nuclear distribution of the proliferating state may, or may not colocalize with weaker FMRP signals which are simply less readily detected. Overall, the general colocalization between RPL7a and EIF4E suggests that EIF4E could very likely colocalize with FMRP as well.

Colocalization assays between PABP (a protein known for binding poly (A) tails of mRNAs) and RPL7a were also made similarly to EIF4E and RPL7a. This series revealed some colocalization between PABP and RPL7a in the cytoplasm, proximal to the nucleus. However, this colocalization appears to decrease, upon filopod elongation, as distance from the nucleus is increased (Figure 4c). PABP seems to remain mostly centrally localized, therefore colocalization with RPL7a (or with FMRP and EIF4E) is at its greatest before the formation of proplatelet structures. Interaction of PABP with the displaced mRNPs is probably most likely to occur in immature MEG-01 cells, or in the earlier stages of mRNP complex assembly. However, the colocalization assays overall suggest that multiple RBPs combine to form rather elaborate mRNP complexes which most importantly involve the translational machinery (translation factors and ribosomes) along with FMRP, which would constitute a massive granule which would appear to interact with microtubules for transport, as has previously been seen in neurons with granular mRNA transport. 


\section{Identifying different types of molecular interactions involved with FMRP}

The use of differently composed denaturing buffers makes it possible to modulate different molecular interactions during the process of cell lysis, prior to differential centrifugation (Supplementary Figure S3a-c). Western Blot analysis of each fraction obtained reflects the state of post-treatment interactions. Here, differentiated MEG-01 cells were lyzed in the presence of the non-ionic detergent NP-40 1\%, as well as that of deoxycholate (DOC) $0.5 \%$, EDTA $50 \mathrm{mM}$, or RNAse $25 \mathrm{U} / \mathrm{ml}$ to interrupt strong ionic bonds, ribosomal subunit association and RNAbound molecules respectively (Figure 5). As can be seen, when MEG-01 cells go from states of proliferation to differentiation, FMRP as well as ribosomes undergo their typical shift from the P100 to P2 fraction. In these same extracts, B-tubulin is polymerized and goes from the soluble fraction S100 toward the P2 cytoskeletal fraction. DOC treatment is strong enough to liberate FMRP from the P2 fraction, freeing it to go to the S100 supernatant, while only partially liberating RPL7a from the P2 towards the P100 fraction. EDTA has little effect on RPL7a distribution of differentiated MEG-01 cells, although it does seem to redistribute FMRP to both the P100 (which still contains some RPL7a) and the S100 fractions. RNAse treatment somewhat increases RPL7a band intensity in the P100 fraction. However, the greatest effect of RNAse is reflected on FMRP's liberation, which leads this protein to accumulate mostly in the S100 fraction. These observations suggest that FMRP's interaction with mRNPs and with the cytoskeleton do in fact occur, as indicated by the colocalization assays. Furthermore, these diverse molecular interactions with FMRP are very unstable, being that they are sensitive to most of the treatments tested, whereas RPL7a seems to be less importantly affected. Protein synthesis 
and its regulation through FMRP's influence would therefore be easily altered in any occurrence of cellular imbalance.

\section{Total protein expression in MEG-01 cells throughout differentiation}

Whole cell content of cytoskeletal and RNA-binding proteins was determined in MEG-01 in proliferation and compared to that of differentiating cells by Western Blot analysis (Figure 6a). As expected, a-actinin, B-tubulin, FMRP and RPL7a were expressed in both, proliferating and differentiating MEG-01 cells. An interesting observation was that both FMRP and B-tubulin in differentiating cells reproducibly revealed additional bands which were not detected in proliferating cells. This suggests either an increased expression of alternative isoforms of these proteins, perhaps required during differentiation; or apoptosis-mediated protease cleavage of these proteins. It is also possible that protein migration may be affected by post-translational modifications, which are triggered by MEG-01 induction. It is not uncommon for cells to alter their protein content in order to adapt to particular conditions, whether they be internal or environmental.

Fluorescence assisted cell sorting was the first technique employed to investigate levels of proteins present in proliferating and differentiating MEG-01 cells. The relative geometrical mean fluorescence intensities of immunofluorescently labelled proteins of interest in MEG-01 cells were graphed to compare total protein levels detected between cell samples. Overall, cellular content of most proteins did not seem to change upon differentiation, with a few exceptions. The unaltered proteins which are stably expressed throughout include FMRP, PABP, a-actinin, and CD42b (Figure 6b). However, a slight increase in GPIIb/IIIa signal was observed, and a very 
noticeable increase in signal intensities for B-tubulin and RPL7a was also observed. This could mean that the expression of these proteins - or other proteins highly involved in cell differentiation - is accentuated in MEG-01 cells beginning to specialize themselves.

\section{De-novo protein synthesis analysis by radio-labelled amino acid incorporation}

To determine whether metabolic alterations occur during cellular differentiation, de-novo protein synthesis in proliferating and differentiating cells was determined by means of (35)S-labelled amino acid incorporation assays. Proteins were then separated by SDS-PAGE and revealed by beta ray detection. The first assay was performed in the absence of FBS and incubated with the radio-labelled amino acids for one hour. Total extracts were obtained for equal amounts of material were loaded in each well of the gel as confirmed by equal intensities of Coomassie coloring (Supplementary Figure S2a). By comparing the relative intensities of total radioactivity signals between proliferating and differentiating MEG-01 cells, a clear decrease in de-novo protein synthesis in differentiated MEG-01 cells was observed in comparison to the superior levels of synthesis in proliferating cells. The analysis of different radioactively-labelled protein bands indicates the presence of a greater amount of proteins synthesized in proliferating cells when compared to those in differentiating cells (Supplementary Figure S2b).

In order to determine whether newly synthesized proteins were differentially located throughout MEG-01 differentiation, (35)S-labelled amino acid incorporation assays followed by differential centrifugations were performed. This second incorporation assay was performed similarly to the first, only this time in the presence of FBS, and was followed by cell lysis and differential centrifugation before loading each fraction acquired on an SDS-PAGE gel (Figure 7). Coomassie 
coloring showed that equal amounts of material were loaded in each lane. The first consideration made upon analysis of radioactive bands was that the difference between the total extracts' overall de-novo protein synthesis rates was greatly amplified by the presence of FBS, which caused proliferating cells to incorporate radio-labelled amino acids at a far greater speed than previously perceived (Figure 7). In general, de-novo protein distribution was mainly detected, in a decreasing order of intensity, in the S100, P2, and minimally in the P100 fractions of both proliferating and differentiating MEG-01 cells (Supplementary Figure S2c). Since a shift in FMRP and RPL7a distribution is known to occur towards the P2 fraction of cells in differentiation, ratios $(\mathrm{S} 100 / \mathrm{P} 2)$ of fractional radioactivity incorporated were compared (Supplementary Figure S2c). As expected from the P2 shift, the comparison of incorporation seems to indicate an augmentation of de-novo protein synthesis content in the cytoskeletal/nuclear P2 fraction. Since the cytoskeleton is so dynamically involved in the maturation of differentiating cells, it seems logical that more newly synthesized proteins should accumulate there to drive and support those changes by providing morphology-altering forces, and mRNP granule transport along microtubules.

\section{$\underline{\text { Discussion }}$}

\section{MEG-01 differentiation with PMA involves the reorganization of the cytoskeleton for}

\section{distinct morphological changes}

PMA-induced MEG-01 differentiation resulted in the same morphological changes as previously described in the literature for this model, bringing MEG-01 cells to release PLPs from fully formed proplatelets. On the other hand, TPO stimulation only triggered the first few stages of differentiation. Thus, PMA induction was selected for MEG-01 activation. As in literature, MEG-01 in proliferation grew rounded, mostly in suspension, with a large nucleus and a typical 
diameter of about $20 \mu \mathrm{m}$ (Thon and Italiano 2012). Upon activation, MEG-01 cells adhered in part to flask surfaces, undergoing endomitosis as it occurs in natural megakaryocytes (MKs) (Baatout et al. 1999), increasing in ploidy to respond to the demand in platelets (Baatout et al. 1998). MKs differentiate to express platelet markers such as GPIIb/IIIa, CD42b and p-selectin (Wang et al. 2012) increasingly as they mature to produce platelets. We showed that these markers were detected in differentiating MEG-01 cells as well.

Following PMA induction, filopods were formed (Hansen et al. 2013) and eventually turned into proplatelets as occurs in MKs from the bone marrow (Thon and Italiano 2012). By immunofluorescent labelling of F-actin and B-tubulin, it was made obvious that proplatelets are formed by an important cytoskeletal reorganization, also observed by Italiano et al. in differentiating MEG-01 cells (Italiano 2013). Preplatelets were gradually formed within proplatelet extremities, resembling the shape of a beaded necklace, before being fragmented, releasing platelet-like particles. Noteworthy, platelet-like particles are composed of specific proteins for platelet functions, as well as mRNAs and the translational machinery for minimal maintenance levels of protein synthesis (Cecchetti et al. 2011). Thus, mRNA localization inside developing preplatelets, as well as specific protein synthesis on location, occurring prior to particle release, must be tightly intertwined mechanisms in this model of differentiation. The requirement of mRNA distribution, as well as local synthesis in MEG-01 cells is similar to that of neuronal cells in development (Antar et al. 2006; Stein et al. 2006).

\section{Protein synthesis is altered during the differentiation of MEG-01 cells}


It was hypothesized that an alteration in protein synthesis should be perceived during differentiation since elements of the translational machinery, transport-related proteins, as well as RNA-regulating proteins, colocalized with FMRP and were so dynamic during these important changes. The change in protein expression would be all the more likely to occur since the switch between proliferating to differentiating states requires the expression of a different subset of proteins, as well as readjusted synthesis rates.

Using the FACS approach, it was determined that most proteins were equally present in both proliferating and differentiating MEG-01 cells, and that only select few proteins (B-tubulin and ribosomal RPL7a) among those tested were expressed more importantly in differentiating cells. This is likely to be the result of an increased involvement in the process of maturation and must consequently be expressed accordingly in order to fulfill the cell's demands. Because the MEG01 differentiation process involves the microtubule-driven formation of proplatelets, and the microtubule-driven transport of translational units to the platelets produced and released, the increased need in B-tubulin and ribosomal protein expression upon induction becomes clear.

Further supporting the increase of B-tubulin observed in differentiating MEG-01 cells, a similar increase in class III B-tubulin in the brain is also known to occur specifically during the differentiation of neurons and has been dosed as a marker for this process in the past (Katsetos et al. 2003; Laferriere and Brown 1996). As in MEG-01 differentiation, the mGluR stimulation preceding neuronal synaptic maturation induces mRNA transport and local synthesis of proteins which are involved in neuronal function. Some of the proteins amplified are dendrite-specific proteins (Kindler and Kreienkamp 2012; Muddashetty et al. 2007). 
Since there appeared to be changes in total protein expression, we wanted to see whether changes in actual de-novo protein synthesis rates occur between proliferating and differentiating MEG-01 cells still remained. (35)S-labelled amino acid incorporation assays in proliferating and differentiated cells showed a drastic decrease in MEG-01 de-novo protein synthesis upon differentiation. This observation was expected, considering that MEG-01 cells in proliferation double their protein content every time cell duplication occurs. Upon differentiation, MEG-01 cells enter a stage of senescence, ending the mitotic cycle, and focusing all of their resources on the rigorous stages of maturation and PLP release, a process known as being apoptotic for the cell (Battinelli et al. 2001). Protein synthesis typically drops to minimal levels of maintenance, where a general and drastic decrease in de-novo protein synthesis occurs.

Differential centrifugations of radio-labelled de-novo proteins show that newly synthesized proteins are similarly distributed throughout MEG-01 cells (either in the soluble S100 fraction or in the nuclear/cytoskeleton-bound P2 fraction) whether they are proliferating or differentiating. Interestingly, the ratio of $\mathrm{P} 2$ over S100 radioactivity shows a shift of newly synthesized proteins towards the P2 fraction of differentiating MEG-01 cells, similar to the FMRP and RPL7a shifts previously observed in Western Blots. This could be due to the sequestration of actively translating polyribosomes to the cytoskeletal fraction while mRNP complexes are being transported by microtubules for local translation. There they would contribute to proper maturation of these dynamic areas as is the case in the synaptic regions of developing neurons.

\section{FMRP and ribosomes are displaced within MEG-01 cells throughout differentiation}


Our study clearly shows, using two different approaches, that FMRP is displaced from the perinuclear region towards developing extremities upon differentiation. The combined observations of FMRP's displacement within the MEG-01 cell are reminiscent of this same protein's behaviour in human neuronal cell lines, as well as mouse brain extracts. In these neuronal models, FMRP co-fractionated with polyribosomes and endoplasmic reticulum, and appeared to localize within branching points and extremities of dendritic spines (Feng et al. 1997). Since the increase in FMRP granular transport in neurons would be induced by mGluR stimulation (Ferrari et al. 2007) during synapse formation, the phenomenon of FMRP displacement upon PMA-induced MEG-01 differentiation could be perceived as a twin consequence of the development triggered in these two unrelated cellular models. The advantage in studying the displacement of FMRP and mRNP complexes from the polyribosomal fraction to the cytoskeletal fraction in MEG-01 cells is that this shift can be induced by simple PMA exposure for one week, during which MEG-01 cells reach full maturity. This provides a much shorter experimental duration in comparison to the FMRP shift which is classically followed during the neurodevelopment of a newborn mouse's brain to its mature adult conformation, a process which lasts for several weeks.

\section{Displacement of mRNP granules containing FMRP over long distances is mostly mediated by microtubules, though dynamic balance between mictrotubules and actin filaments is also required}

Microtubules seems to play a major role in FMRP displacement during MEG-01 differentiation as exemplified by our immunofluorescence colocalization assays. This observation corresponds unsurprisingly to the microtubule-mediated transport of FMRP-containing mRNA granules 
which occurs during neuronal development (Dictenberg et al. 2008; Ferrari et al. 2007; Kindler and Kreienkamp 2012). Microtubules act in fact as a cell's skeleton, strengthening filopodal structures and providing the driving force for their elongation. The expansive microtubular network is a major component required for the long-distance transport of mRNA granules and FMRP away from the nucleus and towards regions of the cell in elongation, which can span long distances (up to $\sim 100 \mu \mathrm{m}$ in MEG-01 cells) (Thon and Italiano 2012). Once mRNP complexes have been brought by microtubular transport in proximity to the extremities, they reach the periphery where actin filaments abound.

However, cytoskeleton modulators assays suggest that although FMRP seems to be transported mainly by microtubules, both components of the cytoskeleton need to be dynamically balanced in order to collaborate during cell maturation and fulfill their respective roles. When this balance is destroyed in MEG-01 cells using either destabilizing agents, proplatelets cannot be formed, preventing FMRP and mRNPs from being properly transported away from the nucleus. The hypothesis that cytoskeletal disruption could interfere with proper mRNP transport was further confirmed by the abnormal distribution of FMRP through the fractions from differential centrifugation done with MEG-01 cells which were differentiated in presence of these cytoskeleton-modulating agents. In each experimental condition, the distribution of FMRP differed from that obtained in non-treated MEG-01 cells. Therefore, large mRNP complexes containing FMRP seem to be displaced along microtubules for long distances and along f-actin for short distances, interacting with molecular motors for transport. In neurons for instance, KIF3A and Calmodulin which are involved in microtubule-mediated transport were found to be present in such complexes (Charalambous et al. 2013). Notably, colchicine treatment on the 
subcellular distribution of FMRP had the most drastic effects of all, supporting the preponderant role of the microtubular network on FMRP displacement. The next point of interest was to determine which sort of interactions stabilized such complexes during their transport throughout cell differentiation.

\section{FMRP is involved in strong ionic interactions with the cytoskeleton, mRNA and polyribosomes}

Several interaction-altering agents were used. EDTA chelated $\mathrm{Mg}^{2+}$ ions present in the cell lysate, dissociating ribosomal subunits, and mRNPs accordingly, since they are normally stabilized as a complex in the presence of $\mathrm{Mg}^{2+}$ ions. In the presence of EDTA, FMRP was largely released from the cytoskeletal fraction and from some bound mRNPs to be redistributed to the polyribosomal and soluble fractions. The solubilization of FMRP suggests that FMRP's association to these structures is partly dependent on the stability of ribosomes within its mRNP complex. This result corresponds to previous observations (Eberhart et al. 1996; Ohashi et al. 2002). RNAse, an enzyme involved in the degradation of RNA, degrades mRNA which holds together RNA-binding proteins of mRNP complexes. It did not seem to affect ribosomal distribution in differentiated MEG-01, though FMRP is noticeably displaced towards the soluble fraction. This confirms that FMRP's interaction with mRNP complexes is highly sensitive to mRNA integrity, as is the case in neurons, where RNAse also freed FMRP from mRNPs (Eberhart et al. 1996; Ohashi et al. 2002).

Most notably, DOC, a strong ionic detergent, interfered with ionic bonds and displaced FMRP from the cytoskeletal P2 pellet towards the S100 fraction as reported previously (Charalambous 
et al. 2013; Khandjian et al. 1996; Khandjian et al. 1995). More intriguingly, ribosomal proteins (RPL7a) were also displaced from the P2 fraction to the ribosomal P100 fraction, supporting that the overall translational machinery is associated with the microtubular network in differentiated MEG-01 cells. These results are in accordance with the great work of Khandjian et al. 2004 which shows that polyribosomes can be easily extracted from a newborn mouse's non-stimulated brain using NP-40, since they are bound to the ER, such as proliferating MEG-01. However, newborn brains are well stimulated and, in accordance with the current results in MEG-01 differentiating cells, neuronal specialization occurs and the translational machinery is displaced from the ER towards the cytoskeletal network. Therefore, polyribosomes are sequestered to the cytoskeletal fraction of stimulated neurons in an adult mouse's brain and the use of DOC becomes mandatory to break ionic bonds and release polyribosomes from the tubular network (Khandjian et al. 1996). Altogether, these results support the validity of the MEG-01 model for further characterization of the displacement of the translational machinery and mRNPs towards the cytoskeleton upon stimulation of differentiation.

As shown above, the current results obtained in MEG-01 cells support the observations made for FMRP interactions during differentiation and are comparable to those from literary examples of previous studies conducted in maturing neurons. It can therefore be hypothesized that in MEG01 cells as in neurons in differentiation, FMRP is trapped within mRNPs inside large polyribosomal complexes that are bound to the cytoskeleton through ionic interactions. Furthermore, these mRNPs may be held together in an RNA-dependent manner, sensitive to ribosomal and mRNA destabilization. The model of granular mRNA transport described by Davidovic et al. (Davidovic et al. 2006) for neurons would likely be found in differentiating 
MEG-01 cells as well, and since the translational machinery is classically involved in these dynamic interactions, one could expect an overall alteration of cellular protein synthesis.

It will be important to acquire an in-depth understanding of the global impacts of FMRP's presence in the system as a whole to account for all of its effects in other tissues of the body. FMRP is a ubiquitously expressed and highly conserved RBP which possesses many functions in common with other members of this family of proteins. Such shared functions appear to be critically involved in the processes of cell differentiation, such as the regulation of translation, mRNA transport and local protein synthesis which leads to cellular asymmetry. FMRP's implication in the regulation and transport of mRNP complexes along the cytoskeleton of differentiating MEG-01 cells appears to be analogous to the behaviours of FMRP observed in developing neurons. The replication of FMRP's function in MEG-01 supports the applicability of another cellular model in the study of the more general functions of this protein. Furthermore, similar molecular dynamics can be observed with other RBPs within different types of cells undergoing polarization and establishment of asymmetrical distribution of cytoplasmic content. Combining FMRP's globally applicable functions along with its polyvalent mRNA binding affinities by simple motif recognition, it becomes clear that FMRP must have the potential to affect all tissues of the human body in a variety of ways during development by interacting intimately with the cytoskeleton and key mRNAs for differentiation.

\section{Conclusion and perspectives}

Mutations within the FMRl gene would therefore impact the human body on a much larger scale than previously anticipated, causing anomalies which should be more profoundly investigated, rather than limiting the focus to the nervous system. The MEG-01 model, here presented for the 
investigation of the global functions of FMRP in cell differentiation, has confirmed the hypothesis that FMRP perpetuates its behaviour in cell models outside of the nervous system by participating in the regulation of local protein synthesis. With such innovative avenues unblocked, and this different perspective on the subject matter, this could be the beginning of a more complete understanding of overall influences of FMRP and other important RBPs in the system as a whole.

\section{$\underline{\text { Acknowledgements }}$}

We would like to thank Leonid Volkov and Audrey Lortie for technical assistance. This work was supported by the Université de Sherbrooke and the Centre de Recherche du CHUS. 


\section{$\underline{\text { References }}$}

Antar, L.N., and Bassell, G.J. 2003. Sunrise at the synapse: the FMRP mRNP shaping the synaptic interface. Neuron 37(4): 555-558.

Antar, L.N., Li, C., Zhang, H., Carroll, R.C., and Bassell, G.J. 2006. Local functions for FMRP in axon growth cone motility and activity-dependent regulation of filopodia and spine synapses. Mol Cell Neurosci 32(1-2): 37-48. doi: 10.1016/j.mcn.2006.02.001.

Ascano, M., Jr., Mukherjee, N., Bandaru, P., Miller, J.B., Nusbaum, J.D., Corcoran, D.L., Langlois, C., Munschauer, M., Dewell, S., Hafner, M., Williams, Z., Ohler, U., and Tuschl, T. 2012. FMRP targets distinct mRNA sequence elements to regulate protein expression. Nature 492(7429): 382-386. doi: 10.1038/nature11737.

Ashley, C.T., Jr., Wilkinson, K.D., Reines, D., and Warren, S.T. 1993. FMR1 protein: conserved RNP family domains and selective RNA binding. Science 262(5133): 563-566.

Baatout, S., Chatelain, B., Staquet, P., Symann, M., and Chatelain, C. 1998. Augmentation of the number of nucleolar organizer regions in human megakaryocyte cell lines after induction of polyploidization by a microtubule inhibitor. Eur J Clin Invest 28(2): 138-144.

Baatout, S., Chatelain, B., Staquet, P., Symann, M., and Chatelain, C. 1999. Interaction between protein kinase $\mathrm{C}$ and actin in megakaryocyte polyploidization. Anticancer Res 19(5B): 41934198.

Bagni, C., and Greenough, W.T. 2005. From mRNP trafficking to spine dysmorphogenesis: the roots of fragile X syndrome. Nat Rev Neurosci 6(5): 376-387. doi: 10.1038/nrn1667.

Bardoni, B., Davidovic, L., Bensaid, M., and Khandjian, E.W. 2006. The fragile X syndrome: exploring its molecular basis and seeking a treatment. Expert Rev Mol Med 8(8): 1-16. doi: $10.1017 /$ S1462399406010751. 
Bassell, G.J., Oleynikov, Y., and Singer, R.H. 1999. The travels of mRNAs through all cells large and small. FASEB J 13(3): 447-454.

Battinelli, E., Willoughby, S.R., Foxall, T., Valeri, C.R., and Loscalzo, J. 2001. Induction of platelet formation from megakaryocytoid cells by nitric oxide. Proc Natl Acad Sci U S A 98(25): 14458-14463. doi: 10.1073/pnas.241427398.

Callan, M.A., Clements, N., Ahrendt, N., and Zarnescu, D.C. 2012. Fragile X Protein is required for inhibition of insulin signaling and regulates glial-dependent neuroblast reactivation in the developing brain. Brain Res 1462: 151-161. doi: 10.1016/j.brainres.2012.03.042.

Cecchetti, L., Tolley, N.D., Michetti, N., Bury, L., Weyrich, A.S., and Gresele, P. 2011. Megakaryocytes differentially sort mRNAs for matrix metalloproteinases and their inhibitors into platelets: a mechanism for regulating synthetic events. Blood 118(7): 1903-1911. doi: 10.1182/blood-2010-12-324517.

Charalambous, D.C., Pasciuto, E., Mercaldo, V., Pilo Boyl, P., Munck, S., Bagni, C., and Santama, N. 2013. KIF1Bbeta transports dendritically localized mRNPs in neurons and is recruited to synapses in an activity-dependent manner. Cell Mol Life Sci 70(2): 335-356. doi: 10.1007/s00018-012-1108-0.

Corbin, F., Bouillon, M., Fortin, A., Morin, S., Rousseau, F., and Khandjian, E.W. 1997. The fragile $\mathrm{X}$ mental retardation protein is associated with poly(A)+ mRNA in actively translating polyribosomes. Hum Mol Genet 6(9): 1465-1472.

Darnell, J.C., and Richter, J.D. 2012. Cytoplasmic RNA-binding proteins and the control of complex brain function. Cold Spring Harb Perspect Biol 4(8): a012344. doi: 10.1101/cshperspect.a012344. 
Darnell, J.C., Van Driesche, S.J., Zhang, C., Hung, K.Y., Mele, A., Fraser, C.E., Stone, E.F., Chen, C., Fak, J.J., Chi, S.W., Licatalosi, D.D., Richter, J.D., and Darnell, R.B. 2011. FMRP stalls ribosomal translocation on mRNAs linked to synaptic function and autism. Cell 146(2): 247-261. doi: 10.1016/j.cell.2011.06.013.

Davidovic, L., Huot, M.E., and Khandjian, E.W. 2005. Lost once, the Fragile X Mental Retardation protein is now back onto brain polyribosomes. RNA Biol 2(1): 1-3.

Davidovic, L., Tremblay, S., Gravel, M., De Koninck, P., and Khandjian, E.W. 2006. [The fragile X syndrome: one protein missing and 1001 disoriented mRNAs]. Med Sci (Paris) 22(1): 41-46. doi: 10.1051/medsci/200622141.

De Boulle, K., Verkerk, A.J., Reyniers, E., Vits, L., Hendrickx, J., Van Roy, B., Van den Bos, F., de Graaff, E., Oostra, B.A., and Willems, P.J. 1993. A point mutation in the FMR-1 gene associated with fragile X mental retardation. Nat Genet 3(1): 31-35. doi: 10.1038/ng0193-31.

Dictenberg, J.B., Swanger, S.A., Antar, L.N., Singer, R.H., and Bassell, G.J. 2008. A direct role for FMRP in activity-dependent dendritic mRNA transport links filopodial-spine morphogenesis to fragile X syndrome. Dev Cell 14(6): 926-939. doi: 10.1016/j.devcel.2008.04.003.

Eberhart, D.E., Malter, H.E., Feng, Y., and Warren, S.T. 1996. The fragile X mental retardation protein is a ribonucleoprotein containing both nuclear localization and nuclear export signals. Hum Mol Genet 5(8): 1083-1091.

Feng, Y., Gutekunst, C.A., Eberhart, D.E., Yi, H., Warren, S.T., and Hersch, S.M. 1997. Fragile $\mathrm{X}$ mental retardation protein: nucleocytoplasmic shuttling and association with somatodendritic ribosomes. J Neurosci 17(5): 1539-1547. 
Ferrari, F., Mercaldo, V., Piccoli, G., Sala, C., Cannata, S., Achsel, T., and Bagni, C. 2007. The fragile X mental retardation protein-RNP granules show an mGluR-dependent localization in the post-synaptic spines. Mol Cell Neurosci 34(3): 343-354. doi: 10.1016/j.mcn.2006.11.015.

Gatto, C.L., and Broadie, K. 2010. Genetic controls balancing excitatory and inhibitory synaptogenesis in neurodevelopmental disorder models. Front Synaptic Neurosci 2: 4. doi: 10.3389/fnsyn.2010.00004.

Hansen, A., Corless, S., Cleland, A., Petrik, J., Gilbert, N., and Bradley, M. 2013. Polymers for the cell-specific immobilisation of megakaryocytic cell lines. Macromol Biosci 13(4): 437-443. doi: 10.1002/mabi.201200368.

Hoeffer, C.A., and Klann, E. 2010. mTOR signaling: at the crossroads of plasticity, memory and disease. Trends Neurosci 33(2): 67-75. doi: 10.1016/j.tins.2009.11.003.

Huang, Y.S., and Richter, J.D. 2004. Regulation of local mRNA translation. Curr Opin Cell Biol 16(3): 308-313. doi: 10.1016/j.ceb.2004.03.002.

Italiano, J.E., Jr. 2013. Unraveling mechanisms that control platelet production. Semin Thromb Hemost 39(1): 15-24. doi: 10.1055/s-0032-1331157.

Katsetos, C.D., Legido, A., Perentes, E., and Mork, S.J. 2003. Class III beta-tubulin isotype: a key cytoskeletal protein at the crossroads of developmental neurobiology and tumor neuropathology. J Child Neurol 18(12): 851-866; discussion 867.

Kelleher, R.J., 3rd, and Bear, M.F. 2008. The autistic neuron: troubled translation? Cell 135(3): 401-406. doi: 10.1016/j.cell.2008.10.017.

Khandjian, E.W., Corbin, F., Woerly, S., and Rousseau, F. 1996. The fragile X mental retardation protein is associated with ribosomes. Nat Genet 12(1): 91-93. doi: 10.1038/ng019691. 
Khandjian, E.W., Fortin, A., Thibodeau, A., Tremblay, S., Cote, F., Devys, D., Mandel, J.L., and Rousseau, F. 1995. A heterogeneous set of FMR1 proteins is widely distributed in mouse tissues and is modulated in cell culture. Hum Mol Genet 4(5): 783-789.

Khandjian, E.W., Huot, M.E., Tremblay, S., Davidovic, L., Mazroui, R., and Bardoni, B. 2004. Biochemical evidence for the association of fragile $\mathrm{X}$ mental retardation protein with brain polyribosomal ribonucleoparticles. Proc Natl Acad Sci U S A 101(36): 13357-13362. doi: 10.1073/pnas.0405398101.

Kindler, S., and Kreienkamp, H.J. 2012. Dendritic mRNA targeting and translation. Adv Exp Med Biol 970: 285-305. doi: 10.1007/978-3-7091-0932-8_13.

Laferriere, N.B., and Brown, D.L. 1996. Expression and posttranslational modification of class III beta-tubulin during neuronal differentiation of P19 embryonal carcinoma cells. Cell Motil Cytoskeleton 35(3): 188-199. doi: 10.1002/(SICI)1097-0169(1996)35:3<188::AID$\mathrm{CM} 2>3.0 . \mathrm{CO} ; 2-5$.

Muddashetty, R.S., Kelic, S., Gross, C., Xu, M., and Bassell, G.J. 2007. Dysregulated metabotropic glutamate receptor-dependent translation of AMPA receptor and postsynaptic density-95 mRNAs at synapses in a mouse model of fragile X syndrome. J Neurosci 27(20): 5338-5348. doi: 10.1523/JNEUROSCI.0937-07.2007.

Muller, M., Heuck, A., and Niessing, D. 2007. Directional mRNA transport in eukaryotes: lessons from yeast. Cell Mol Life Sci 64(2): 171-180. doi: 10.1007/s00018-006-6286-1.

O'Donnell, W.T., and Warren, S.T. 2002. A decade of molecular studies of fragile X syndrome. Annu Rev Neurosci 25: 315-338. doi: 10.1146/annurev.neuro.25.112701.142909.

Ohashi, S., Koike, K., Omori, A., Ichinose, S., Ohara, S., Kobayashi, S., Sato, T.A., and Anzai, K. 2002. Identification of mRNA/protein (mRNP) complexes containing Puralpha, mStaufen, 
fragile $\mathrm{X}$ protein, and myosin $\mathrm{Va}$ and their association with rough endoplasmic reticulum equipped with a kinesin motor. J Biol Chem 277(40): 37804-37810. doi: 10.1074/jbc.M203608200.

Oostra, B. A., \& Nelson, D. L. (2006). Chapter 11 - animal models of fragile X syndrome: Mice and flies. In Robert D. Wells, \& Tetsuo Ashizawa (Eds.), Genetic instabilities and neurological diseases (second edition) (pp. 175-193). Burlington: Academic Press. doi: http://dx.doi.org/10.1016/B978-012369462-1/50012-0

Pratt, C.A., and Mowry, K.L. 2013. Taking a cellular road-trip: mRNA transport and anchoring. Curr Opin Cell Biol 25(1): 99-106. doi: 10.1016/j.ceb.2012.08.015.

Qurashi, A., Li, X., and Jin, P. 2012. Fragile X mental retardation protein and stem cells. Results Probl Cell Differ 54: 157-164. doi: 10.1007/978-3-642-21649-7_8.

Saldarriaga, W., Tassone, F., Gonzalez-Teshima, L.Y., Forero-Forero, J.V., Ayala-Zapata, S., and Hagerman, R. 2014. Fragile X syndrome. Colomb Med (Cali) 45(4): 190-198.

Stein, J.M., Bergman, W., Fang, Y., Davison, L., Brensinger, C., Robinson, M.B., Hecht, N.B., and Abel, T. 2006. Behavioral and neurochemical alterations in mice lacking the RNA-binding protein translin. J Neurosci 26(8): 2184-2196. doi: 10.1523/JNEUROSCI.4437-05.2006.

Takahashi, N., Tarumi, W., Itoh, M.T., and Ishizuka, B. 2015. The Stage- and Cell Type-Specific Localization of Fragile X Mental Retardation Protein in Rat Ovaries. Reprod Sci. doi: $10.1177 / 1933719115589416$.

Thon, J.N., and Italiano, J.E. 2012. Platelets: production, morphology and ultrastructure. Handb Exp Pharmacol(210): 3-22. doi: 10.1007/978-3-642-29423-5_1. 
Wang, Y., Andrews, M., Yang, Y., Lang, S., Jin, J.W., Cameron-Vendrig, A., Zhu, G., Reheman, A., and Ni, H. 2012. Platelets in thrombosis and hemostasis: old topic with new mechanisms. Cardiovasc Hematol Disord Drug Targets 12(2): 126-132.

Xing, L., and Bassell, G.J. 2013. mRNA localization: an orchestration of assembly, traffic and synthesis. Traffic 14(1): 2-14. doi: 10.1111/tra.12004.

Xu, H., Rosales-Reynoso, M.A., Barros-Nunez, P., and Peprah, E. 2013. DNA repair/replication transcripts are down regulated in patients with Fragile X Syndrome. BMC Res Notes 6: 90. doi: 10.1186/1756-0500-6-90. 


\section{Figure captions}

Figure 1: Microscopic and immunofluorescent characterization of MEG-01 cells induced by PMA.

Images obtained by confocal microscopy of immunofluorescently labelled MEG-01 cells identified at various different stages of differentiation according to morphology. From left to right and starting at the top are images captured of MEG-01 in proliferation in suspension, followed by an activated cell whose cytoskeleton is redistributed during proliferation arrest and endomitosis. Polyploidy is shown as there is appearance of more than one nucleus in one given cell. Filament polymerization is made obvious in the following image where the cytoplasm begins to expand away from the nucleus. Filopods begin to be shaped as the cytoskeleton extends with evident cellular polarity. Filopods are then elongated to form proplatelets, which finally mature and give rise to very characteristic platelet-like particles to be released at extremities. Labelling: nucleus (blue), actin filaments (green) and FMRP (red). White bar: $10 \mu \mathrm{m}$ scale.

Figure 2: Western Blot analyses of cellular fractions of MEG-01 lysates obtained by differential centrifugation and sucrose gradient fractionation.

a) WB of differential centrifugation fractions P2, P16, P100 and S100. FMRP distribution in the P2 and P100 fractions of proliferating MEG-01 cells is shifted mostly to the P2 fraction in differentiating cells. Ribosomes labelled by RPL7a also undergo a similar change in subcellular distribution.

b) Absorbance curve $(254 \mathrm{~nm})$ and Western Blot analysis protein content in fractions obtained from for post-nuclear MEG-01 lysate separated on a sucrose gradient. Proliferating MEG-01 give the traditional curve for protein distribution shown by a solid line, representing ribosomal $40 \mathrm{~S}, 60 \mathrm{~S}$ and $80 \mathrm{~S}$ as well as polyribosomes from left to right (least dense to densest fractions). In differentiating MEG-01, polyribosomes are not detected by absorbance readings and FMRP as well as RPL7a are absent from the typical polyribosomal fractions of the gradient. 


\section{Figure 3: Colocalization studies with FMRP in resting and stimulated MEG01 cells}

a) Colocalization between FMRP and B-tubulin by confocal microscopy (immunofluorescence) throughout MEG-01 differentiation. FMRP is shown to colocalize with B-tubulin throughout all steps of differentiation in concert with morphological changes. Labelling: B-tubulin (green), FMRP (red), nucleus (blue). Colocalization between B-tubulin and FMRP is highlighted in white. White bar: $10 \mu \mathrm{m}$ scale.

b) Colocalization between FMRP and F-actin by confocal microscopy (immunofluorescence) in differentiated MEG-01. Colocalization between FMRP and F-actin is minimal and limited mostly to the nuclear and peripheral contours of the MEG-01 cell. Labelling: F-actin (green), FMRP (red), nucleus (blue). Colocalization between the two proteins labelled is highlighted in white. White bar: $10 \mu \mathrm{m}$ scale.

c) Colocalization between FMRP and Calnexin by confocal microscopy (immunofluorescence) in differentiating MEG-01. Colocalization between FMRP and Calnexin is somewhat important and particularly intense around the nucleus as well as in cone-shaped openings of filopodal extensions. It does not, however, reach extremities as far out as FMRP signal alone does. Labelling: Calnexin (green), FMRP (red), nucleus (blue). Colocalization between Calnexin and FMRP is highlighted in white. White bar: $10 \mu \mathrm{m}$ scale.

\section{Figure 4: Colocalization studies of FMRP with other RBPs in differentiating MEG-01 cells.}

a) Colocalization of FMRP with RPL7a throughout MEG-01 differentiation. FMRP colocalizes perfectly with RPL7a, as made evident by colocalization, which is highlighted in white and by the plot graph for colocalization which forms a straight diagonal curve. Labelling: RPL7a (green), FMRP (red), nucleus (blue). White bar: $10 \mu \mathrm{m}$ scale.

b) Colocalization of EIF4E with RPL7a throughout MEG-01 differentiation. EIF4E colocalizes with RPL7a particularly upon activation, as demonstrated by colocalization highlighted in white and by the plot graph above for colocalization which is represented by a diagonal curve when 
EIF4E if cytoplasmically distributed. Labelling: RPL7a (green), EIF4E (red), nucleus (blue). White bar: $10 \mu \mathrm{m}$ scale.

c) Colocalization of PABP with RPL7a throughout MEG-01 differentiation. A PABP-RPL7a colocalization is most evident in the cytoplasm, in proximity to the nucleus, decreasing in degree as cytoplasm extended away from the nucleus. Labelling: RPL7a (green), PABP (red), nucleus (blue). The colocalization plot graph above forms a diagonal if colocalization occurs, though in this case it is made less obvious in differentiated cells. White bar: $10 \mu \mathrm{m}$ scale.

\section{Figure 5: Biochemical determination of molecular interactions involved with FMRP in resting and stimulated MEG-01 cells.}

Shown is a Western Blot analysis of differential centrifugation fractions of MEG-01 lysates obtained after exposure to different interaction-interrupting agents. As described in the text, MEG-01 cells were lyzed in standard buffer with NP-40, DOC buffer, EDTA buffer and RNAse buffer. Ribosomes were only minimally affected in their distribution with RPL7a being displaced from P2 towards the P100 by DOC and RNAse. On the other hand, FMRP is very sensitive to treatment and is directly solubilized by DOC treatment and RNAse, while EDTA increases its presence in P100 as well as S100. B-tubulin is displaced from S100 to P2 while FMRP and RPL7a leave the P100 fraction to increase in intensity in P2 upon differentiation of cells.

Figure 6: Analysis of total protein content detected in MEG-01 cells in proliferation and differentiation.

a) Protein content of total extracts from proliferating and differentiating MEG-01 cells. These four proteins identified by Western Blot analyses reveal the appearance of alternative bands for FMRP and B-tubulin, which are only visible in activated MEG-01 cells.

b) FACS-determined relative mean geometrical intensities of fluorescence readings detected in MEG-01 cells. No significant increase in geometrical mean fluorescence intensity occurred for FMRP, PABP, a-actinin, CD42b and GPIIb/IIIa. RPL7a and B-tubulin content on a per cell basis seems however to increase considerably upon cell activation. 
Figure 7: Determination of de-novo protein synthesis by (35)S labelled amino acid incorporation assays.

(35)S amino acid incorporation assay results for total extracts and differential centrifugation fractions from proliferating and differentiating MEG-01 cells (with FBS).The Coomassielabelled gel shows that equal amounts of total proteins (confirmed by cell counting at the microscope) were dropped in each well for migration. Small amounts of protein appear to be present in P100 of proliferating cells. Second from the left is the image of radio-labelled bands of incorporated amino acids after a one-hour incubation in the presence of FBS, showing decreased overall signal intensity in all lanes for differentiated cells. Although some proteins are detected in P100 of radio-labelled differentiated MEG-01, the greater part of de-novo protein synthesis is distributed similarly (in S100 and P2) between proliferating and differentiated cells. Differences in total de-novo protein synthesis between proliferating and differentiated cells are made all the more obvious by incubation in the presence of FBS, according to total extracts. 
1.

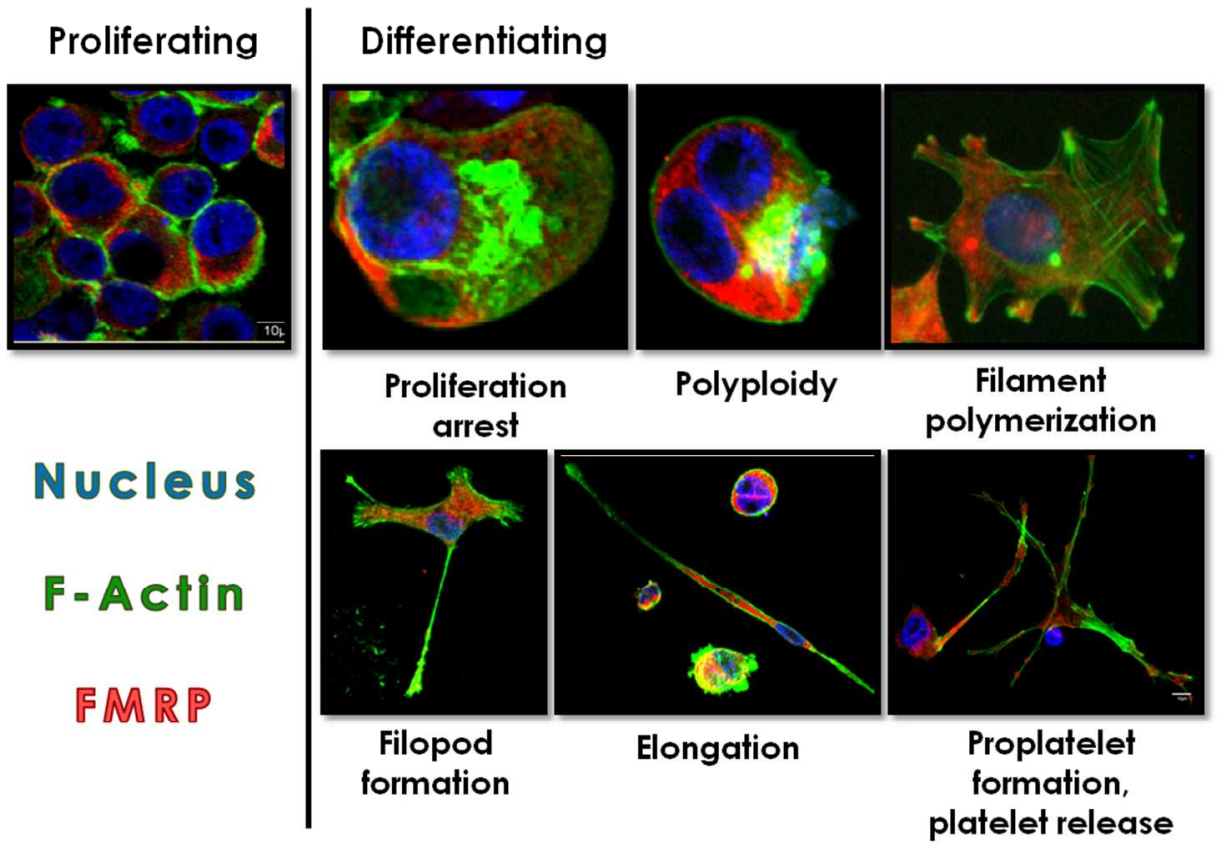

Figure 1: Microscopic and immunofluorescent characterization of MEG-01 cells induced by PMA $196 \times 140 \mathrm{~mm}(150 \times 150 \mathrm{DPI})$ 
2.

a)

\begin{tabular}{|l|l|ll|c|}
\hline \multicolumn{4}{|c|}{ Differential Centrifugations (Western Blot) } \\
\hline- & & & $\begin{array}{c}\text { a-Actinin } \\
100 \mathrm{kDa}\end{array}$ \\
\hline & & & $\begin{array}{c}\text { FMRP } \\
\text { Isoforms } \\
80 \mathrm{kDa}\end{array}$ \\
\hline P2 P16 P100 S100 & P2 P16 P100 S100 & \\
\hline Proliferating MEG-01 & Differentiating MEG-01 & \\
\hline
\end{tabular}

b)

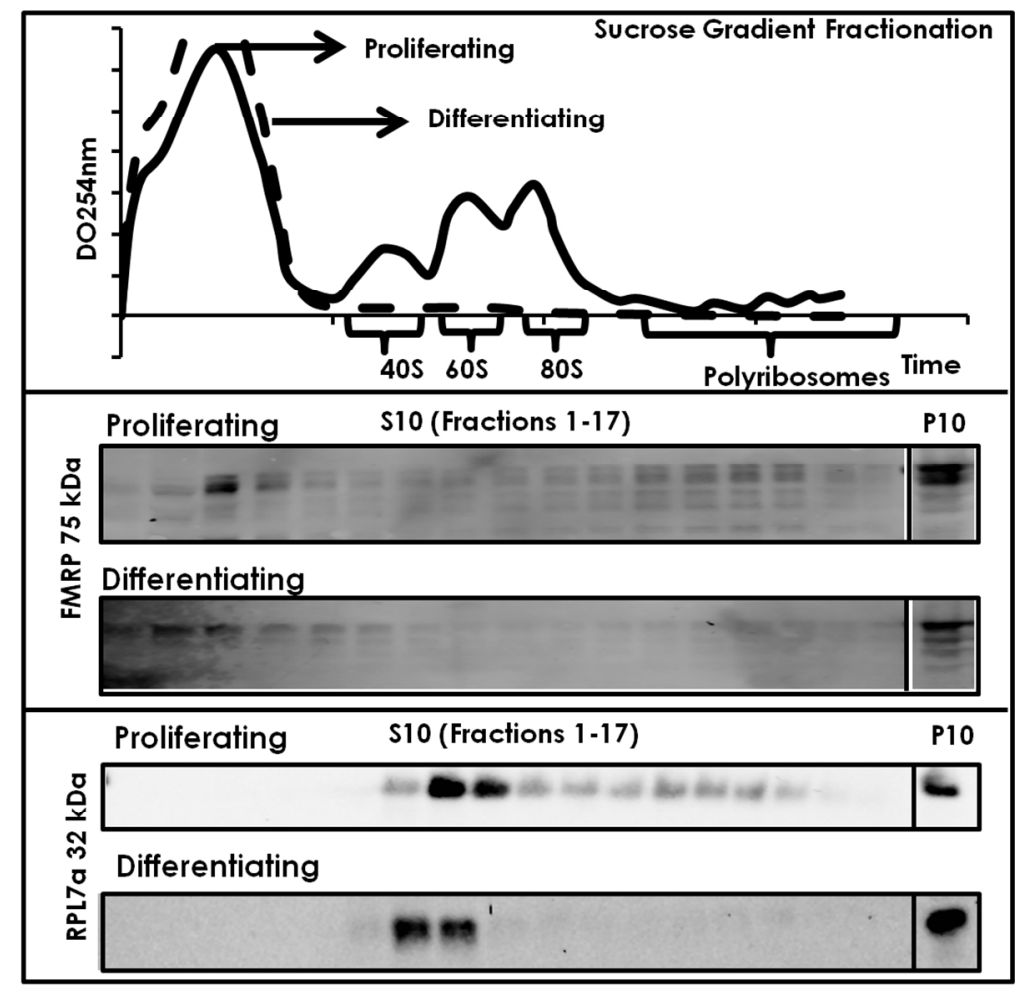

Figure 2: Western Blot analyses of cellular fractions of MEG-01 lysates obtained by differential centrifugation and sucrose gradient fractionation. $184 \times 287 \mathrm{~mm}(150 \times 150 \mathrm{DPI})$ 
3.

a)

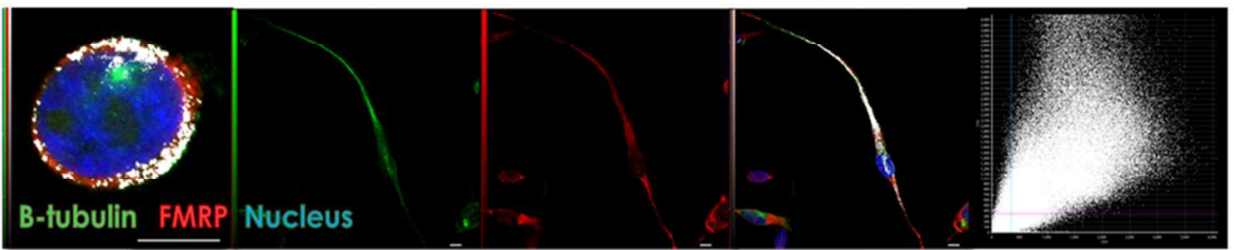

b)

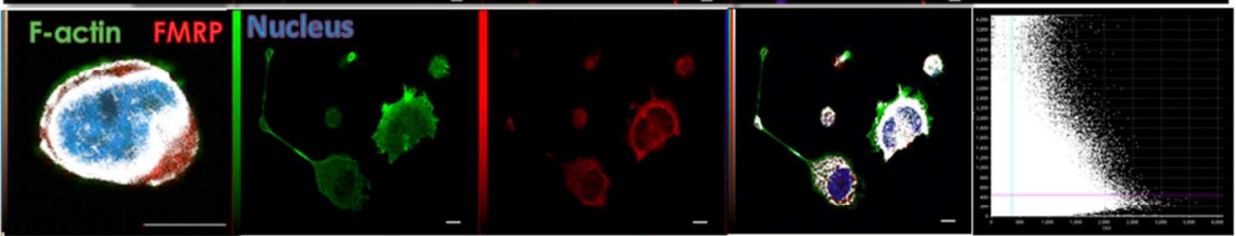

c)

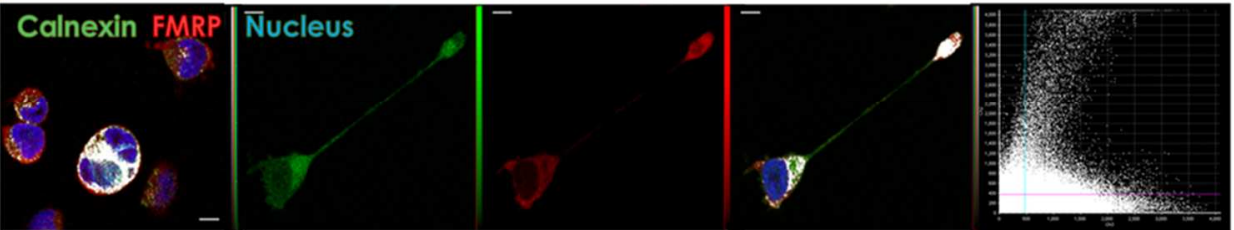

Figure 3: Colocalization studies with FMRP in resting and stimulated MEG01 cells $182 \times 113 \mathrm{~mm}(150 \times 150 \mathrm{DPI})$ 
4.

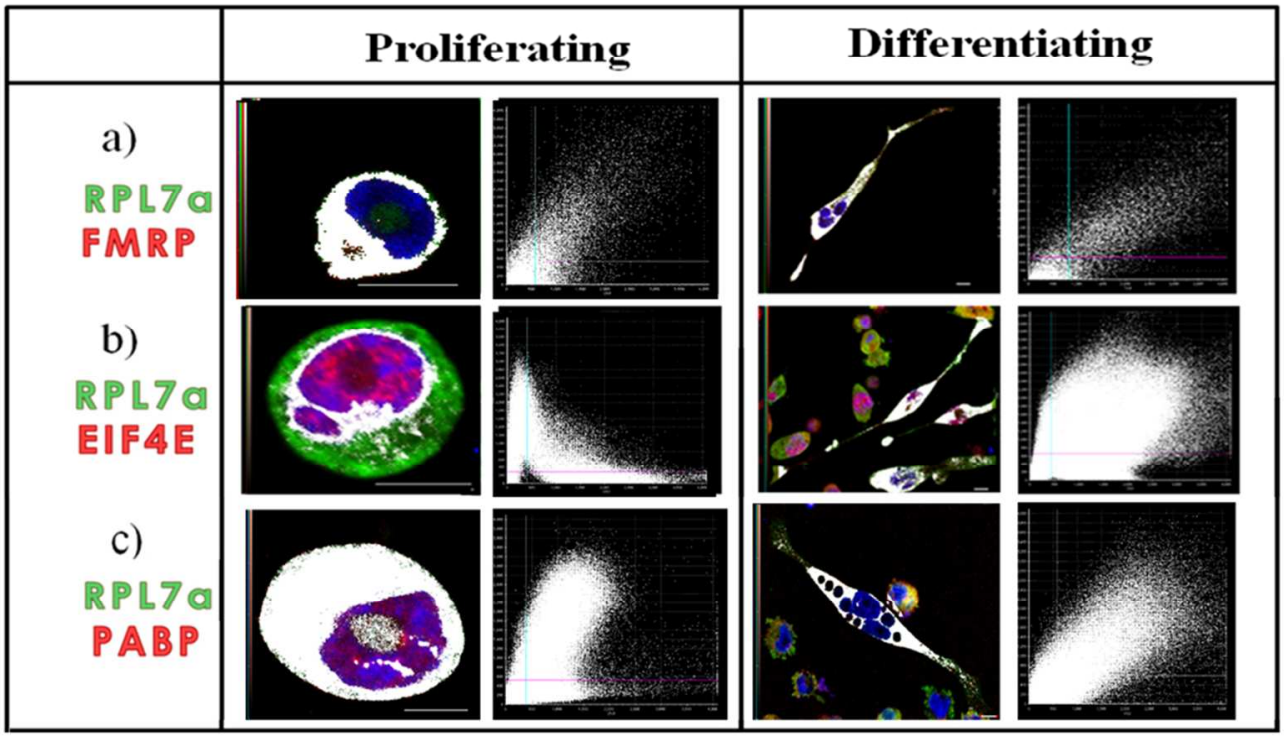

Figure 4: Colocalization studies of FMRP with other RBPs in differentiating MEG-01 cells. $182 \times 113 \mathrm{~mm}(150 \times 150 \mathrm{DPI})$ 
5.

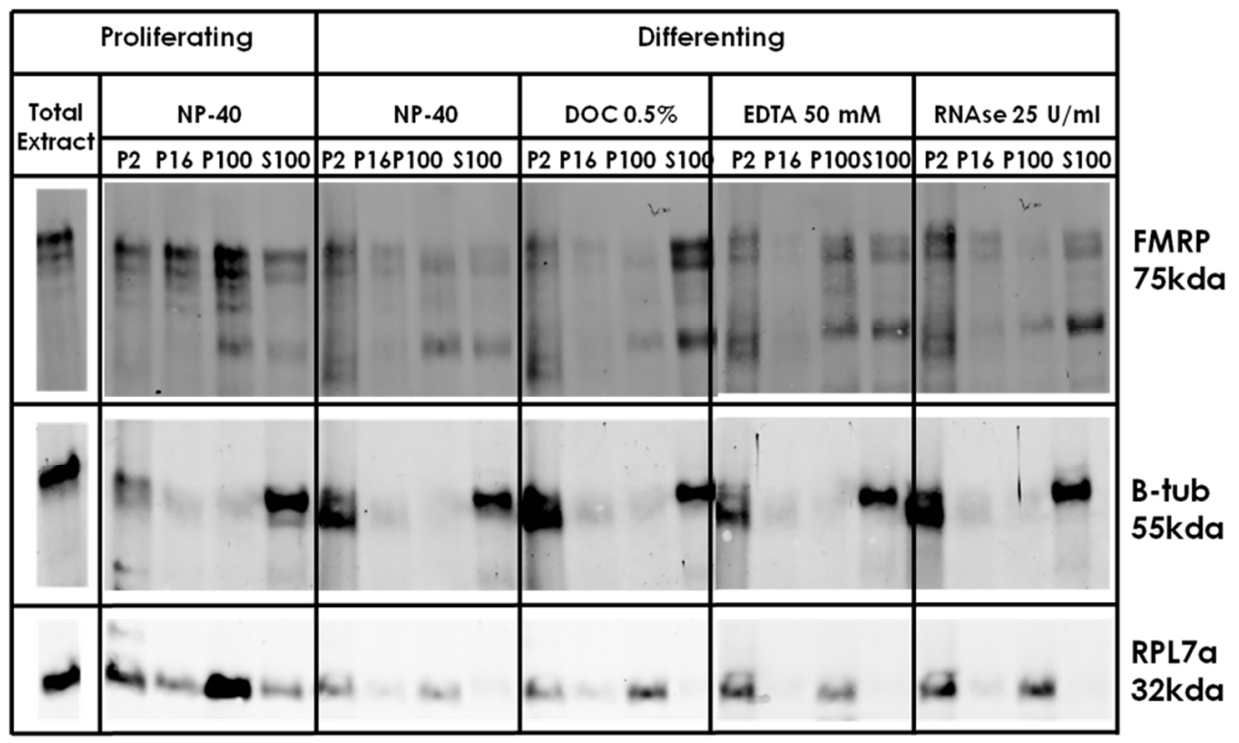

Figure 5: Biochemical determination of molecular interactions involved with FMRP in resting and stimulated MEG-01 cells

$182 \times 114 \mathrm{~mm}(150 \times 150 \mathrm{DPI})$ 
6.

a)

\begin{tabular}{|l|c|}
\hline \multicolumn{2}{|c|}{ Western Blot } \\
\hline P D & \\
\hline-- & $\begin{array}{c}\text { A-act } \\
100 \mathrm{kDa}\end{array}$ \\
\hline- & FMRP \\
\hline & $75 \mathrm{kDa}$ \\
\hline$-=$ & B-Tub \\
& $55 \mathrm{kDa}$ \\
\hline- & RPL7a \\
$32 \mathrm{kDa}$ \\
\hline
\end{tabular}

b)

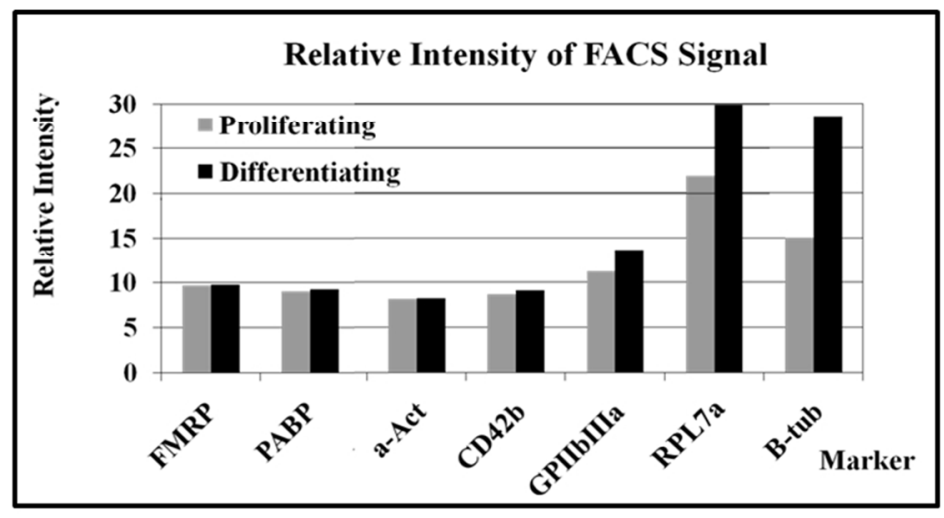

Figure 6: Analysis of total protein content detected in MEG-01 cells during proliferation and differentiation $184 \times 94 \mathrm{~mm}(150 \times 150 \mathrm{DPI})$ 
7.

Coomassie

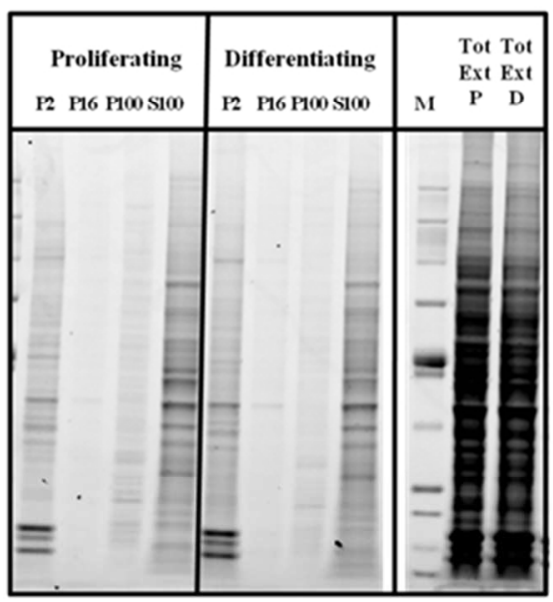

\section{Incorporated (35)S}

$-250 \mathrm{kDa}$ -

$-150 \mathrm{kDa}-$

$-100 \mathrm{kDa}$ -

$-75 \mathrm{kDa}-$

$-50 \mathrm{kDa}-$

$-37 \mathrm{kDa}-$

$-25 \mathrm{kDa}-$

$-20 \mathrm{kDa}-$

$-15 \mathrm{kDa}-$

$-10 \mathrm{kDa}-$

\begin{tabular}{|c|c|c|}
\hline $\begin{array}{l}\text { Proliferating } \\
\text { F2 P16 P100 S10 }\end{array}$ & $\begin{array}{l}\text { Differentiating } \\
\text { P2 P16 P100 S10 }\end{array}$ & $\begin{array}{r}\text { Tot Tot } \\
\text { Ext Ext } \\
\text { M P D }\end{array}$ \\
\hline$E$ & 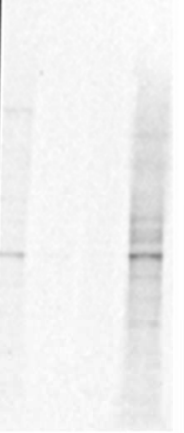 & H \\
\hline
\end{tabular}

Figure 7: Determination of de-novo protein synthesis by (35)S labelled amino acid incorporation assays $182 \times 104 \mathrm{~mm}(150 \times 150 \mathrm{DPI})$ 